\section{RSP}

http://www.rsp.fsp.usp.br/
Revista de Saúde Pública

\title{
Maternal mental health and nutritional status of six-month-old infants
}

\author{
Bruna Kulik Hassan', Guilherme Loureiro Werneck", Maria Helena Hasselmann"II \\ I Programa de Pós-Graduação em Saúde Coletiva. Instituto de Medicina Social. Universidade do Estado do Rio \\ de Janeiro. Rio de Janeiro, RJ, Brasil \\ " Departamento de Epidemiologia. Instituto de Medicina Social. Universidade do Estado do Rio de Janeiro. Rio \\ de Janeiro, RJ, Brasil \\ III Departamento de Nutrição Social. Instituto de Nutrição. Universidade do Estado do Rio de Janeiro. Rio de \\ Janeiro, RJ, Brasil
}

\section{ABSTRACT}

OBJECTIVE: To analyze if maternal mental health is associated with infant nutritional status at six month of age.

METHODS: A cross-sectional study with 228 six-month-old infants who used primary health care units of the city of Rio de Janeiro, Southeastern Brazil. Mean weight-for-length and mean weightfor-age were expressed in z-scores considering the 2006 World Health Organization reference curves. Maternal mental health was measured by the 12 -item General Health Questionnaire. The following cutoff points were used: $\geq 3$ for common mental disorders, $\geq 5$ for more severe mental disorders, and $\geq 9$ for depression. The statistical analysis employed adjusted linear regression models.

RESULTS: The prevalence of common mental disorders, more severe mental disorders and depression was $39.9 \%, 23.7 \%$, and $8.3 \%$, respectively. Children of women with more severe mental disorders had, on average, a weight-for-length $0.37 \mathrm{z}$-scores lower than children of women without this health harm $(\mathrm{p}=0.026)$. We also observed that the weight-for-length indicator of children of depressed mothers was, on average, $0.67 \mathrm{z}$-scores lower than that of children of nondepressed women $(p=0.010)$. Maternal depression was associated with lower mean values of weight-forage z-scores $(p=0.041)$.

Correspondence:

Rua São Francisco Xavier, $5247^{\circ}$ andar Maracanã

20550-900 Rio de Janeiro, RJ,

Brasil

E-mail: bkulik@gmail.com

\section{Received: 4 Mar 2015}

Approved: 22 Ago 2015

How to cite: Hassan BK, Werneck GL, Hasselmann MH. Maternal mental health and nutritional status of six-month-old infants. Rev Saude Publica. 2016;50:7.

Copyright: This is an open-access article distributed under the terms of the Creative Commons Attribution License, which permits unrestricted use, distribution, and reproduction in any medium, provided that the original author and source are credited.
CONCLUSIONS: Maternal mental health is positively related to the inadequacy of the nutritional status of infants at six months.

DESCRIPTORS: Maternal Welfare, psychology. Mental Health. Postpartum Period. Depression, Postpartum. Infant Nutrition. Mother-Child Relations. Cross-Sectional Studies. 


\section{INTRODUCTION}

Child malnutrition persists as a major public health problem in developing countries, contributing to $1 / 3$ of under-five deaths ${ }^{28}$. According to estimates from six cohort studies in developing countries, its eradication could prevent a million deaths from pneumonia, 800 thousand from diarrhoea, 500 thousand from malaria and 200 thousand from measles ${ }^{2}$.

According to joint data from the United Nations Children's Fund (UNICEF), the World Bank, and the World Health Organization (WHO), 161 million children under the age of five were stunted in 2013, which is equivalent to $25.0 \%$ of the world population ${ }^{23}$. Although Brazil presents a better current situation regarding child malnutrition, with $6.0 \%$ of children under five years of age stunted, the distribution of this indicator is uneven, with a higher prevalence in the North (8.5\%), in children under one year of age $(8.8 \%)$ and among those who live in families with a monthly per capita income of up to $1 / 4$ of the minimum wage $(8.2 \%)^{10}$.

There is extensive literature on determinants of child growth. The most important are social, economic and environmental factors such as parents' educational attainment and housing conditions, maternal age and work, family size, birth weight, recurrent infections and dietary habits ${ }^{16,30}$.

Such evidence does not solve, however, the issue of inadequate child growth determination. Even after the socioeconomic and demographic changes and improvement in the care provided by health services in the last decades, there are still children with nutritional deficits in developing countries ${ }^{28,29}$. In addition, family members under the same conditions of life and living in the same house have different nutritional status ${ }^{11}$.

In this regard, investigations have focused on the contribution of psychosocial aspects in the process, pointing to alcoholism and lack of social support, as well as aspects related to motherhood, such as factors associated with nutritional deficits in childhood ${ }^{1,26}$. Some studies suggest that factors present within the family environment could negatively affect the maternal capacity to provide adequate care for the child, contributing to child malnutrition ${ }^{1,26}$.

Although increasing, the literature addressing the impact of maternal mental health on children's nutritional status has contradictory results. While some studies showed a worse growth pattern in children whose mothers presented some psychological disorder when compared with the children of women without disorders, other investigations conducted in developing countries did not show significant differences for this relation ${ }^{6,18,19,22}$. To clarify this issue, the objective of the present study was to examine whether maternal mental health is associated with child nutritional status in the sixth month of life.

\section{METHODS}

This cross-sectional study is part of a prospective cohort whose central objective is to investigate the social determinants of the growth of children in the first year of life.

Its population is composed of newborns who used four primary health care units of the municipality of Rio de Janeiro, Southeastern Brazil, at the time of vaccination (BCG) or Guthrie test, referred directly from the maternity hospitals where they were born, as recommended by the Rio de Janeiro Municipal Health Department (SMS-RJ) program "Acolhimento mãe-bebê" (Mother-baby welcoming). Primary health care units were chosen intentionally, considering the average number of newborns registered in the program every month and the geographical variability, to represent different population groups.

The information relating to the first interview ( first month) and to the one six months after birth were included in this study. Excluding those with congenital anomalies, cerebral palsy 
and six twins, 228 children composed the sample. Throughout data collection, between June 2005 and June 2008, the principal investigator of the research supervised the interviewers. Questionnaires with closed, precoded questions, and other open or semi-open questions were applied in face-to-face interviews with the children's mothers.

To obtain the outcome variables reflecting the child's nutritional status, the weight and length of children at six months of age were measured without any clothing or accessories. Weight was measured using a Filizola pediatric scale with a maximum capacity of $15 \mathrm{~kg}(0.1$ $\mathrm{kg}$ resolution). Length was measured using a wooden horizontal infant stadiometer specially constructed for the study ( $1 \mathrm{~mm}$ resolution). The anthropometric training consisted of the following steps: (a) introduction on nutritional assessment of children under two years of age; (b) theoretical presentation of the techniques for weighing and measuring children under two years of age; and (c) standardization of anthropometric measurements, a procedure recommended by Habicht ${ }^{5}$ (1974). Based on these measurements, we estimated the variables weight-for-length and weight-for-age according to sex, expressed as z-scores, using the new growth chart for children under five ${ }^{31}$.

To assess maternal mental health six months after giving birth, we used the Brazilian Portuguese adapted and validated version of the 12-item General Health Questionnaire (GHQ-12) $)^{12}$. This instrument uses the two weeks before filling the questionnaire as reference period and reflects feelings of depression and anxiety, inability to cope with usual situations and lack of confidence ${ }^{4}$.

Each item of GHQ-12 contains four response options, the first two considering the recent experience of the participant in relation to a particular symptom or behavior as absent ( 0 points assigned) and the last two as present ( 1 point assigned). Thus, summing the points of each item generates a scale from zero to 12 possible points. Three variables were established to assess maternal mental health with this instrument. The variable common mental disorders (CMD) was set from the cut-off point of at least three positive responses. This cut-off point shows good sensitivity (85.0\%), without any significant loss of specificity $(79.0 \%)^{12}$. The variable more severe mental disorders was identified by the cut-off point of at least five positive responses. Villano ${ }^{a}$ found a $76.0 \%$ sensitivity and a $59.0 \%$ specificity for this cut-off point in an outpatient clinic of a university hospital in Rio de Janeiro. Finally, for the variable depression we used the cut-off point of at least nine positive items, as in the study by Ozdemir and Remaki ${ }^{17}$, who found a $75.0 \%$ sensitivity and a $77.0 \%$ specificity.

The covariables investigated were: maternal age ( $<$ or $\geq 20$ years), maternal work (yes or no), prematurity (yes or no), birth weight (in grams), number of children under five years of age, mother's educational attainment (full years of schooling) and social network. To evaluate the social network, participants were asked "how many friends do you feel comfortable with and can talk about almost anything?" and "how many relatives do you feel comfortable with and can talk about almost anything?". We subsequently added the number of relatives and friends mentioned to compose this variable.

Initially, we estimated the mean z-scores for outcomes along with the prevalence of exposure variables as well as sociodemographic, child, and maternal characteristics. Crude analyses used simple linear regression (categorical covariables and central exposure variables) and Spearman's correlation test (numerical covariables). In multivariate analysis, linear regression models were adjusted by the covariables presenting associations of $\mathrm{p} \leq 0.20$ in the crude analyses.

a Villano LA. Problemas psicológicos e morbidade psiquiátrica em serviços de saúde não-psiquiátricos: o ambulatório de clínica geral [these]. São Paulo (SP): Universidade Federal de São Paulo; 1998.
Three methods of diagnosis of the regression models were used to evaluate the quality of fit: Q-Q plot, studentized residuals versus predicted values graphs, and Cook's distance. All multivariate models showed good fit and only one outlier was found, but maintained in the analysis.

Data were stored in the application EpiInfo version 6.04 and analyzed in statistical packages $\mathrm{R}$ version 2.9.0 and Stata version 9.2. The software WHO Anthro version 3.0.1 was used to estimate the indexes weight-for-length and weight-for-age. 
The study was approved by the Ethics Committee of the Instituto de Medicina Social of the Universidade do Estado do Rio de Janeiro. Mothers needed to sign an informed consent form to participate in the study.

\section{RESULTS}

Table 1 presents the characteristics of the study population. The children's mean age was 6.46 months, and $52.4 \%$ of the sample were boys. The minority of the children were premature and had low birth weight. For the indexes weight-for-length and weight-for-age, the mean z-scores were 0.23 and 0.05 , respectively.

Mother's mean age was 25.5 years. They also had, on average, 8.5 years of schooling, 1.24 children and 3.67 friends or relatives who they could trust to tell almost everything (social network). There was a high percentage of adult women who were not working at the time of the interview. Approximately $40.0 \%$ of mothers were detected with CMD, 24.0\% with more severe mental disorders, and 8.0 percent with depression.

Table 1. Characteristics of the study population. Rio de Janeiro, RJ, Southeastern Brazil, 2005-2008.

\begin{tabular}{|c|c|c|}
\hline Categorical variables & n* & $\%$ \\
\hline \multicolumn{3}{|l|}{ Sex } \\
\hline Male & 122 & 52.4 \\
\hline Female & 111 & 47.2 \\
\hline \multicolumn{3}{|l|}{ Birth weight (grams) } \\
\hline $\operatorname{Low}(<2,500)$ & 16 & 6.9 \\
\hline Adequate $(\geq 2,500)$ & 216 & 93.1 \\
\hline \multicolumn{3}{|l|}{ Prematurity } \\
\hline No & 199 & 90.9 \\
\hline Yes & 20 & 9.1 \\
\hline \multicolumn{3}{|l|}{ Maternal work } \\
\hline No & 157 & 71.7 \\
\hline Yes & 62 & 28.3 \\
\hline \multicolumn{3}{|l|}{ Maternal age (years) } \\
\hline$\geq 20$ & 173 & 77.2 \\
\hline$<20$ & 51 & 22.8 \\
\hline \multicolumn{3}{|l|}{ CMD (GHQ-12) } \\
\hline No $(<3)$ & 137 & 60.1 \\
\hline Yes $(\geq 3)$ & 91 & 39.9 \\
\hline \multicolumn{3}{|l|}{ More severe disorders (GHQ-12) } \\
\hline No $(<5)$ & 174 & 76.3 \\
\hline Yes $(\geq 5)$ & 54 & 23.7 \\
\hline \multicolumn{3}{|l|}{ Depression (GHQ-12) } \\
\hline No $(<9)$ & 209 & 91.7 \\
\hline Yes $(\geq 9)$ & 19 & 8.3 \\
\hline Numeric variables & Mean & SD \\
\hline Weight-for-length & 0.23 & 1.08 \\
\hline Weight-for-age & 0.05 & 1.07 \\
\hline Birth weight (grams) & 3.21 & 0.48 \\
\hline Child's age (months) & 6.46 & 0.80 \\
\hline Maternal age (years) & 25.5 & 6.57 \\
\hline Maternal education (years of schooling) & 8.49 & 2.81 \\
\hline Number of children $<5$ years of age & 1.24 & 0.46 \\
\hline Social network (friends and relatives) & 3.67 & 2.87 \\
\hline
\end{tabular}

* Totals may vary due to missing values in some variables. 
In the crude analysis (Tables 2 and 3), only birth weight was significantly associated with weight-for-length and weight-for-age, and was the variable selected to be included in the multiple linear regression models.

The crude and adjusted associations between exposure variables and children's nutritional status are shown in Table 4. More severe mental disorders and depression were associated with lower average weight-for-length z-scores (Table 4). Children of women with more severe mental disorders had, on average, a weight-for-length $0.37 \mathrm{z}$-scores lower than children of women without this health condition $(p=0.026)$. Children of women with depression had, on average, $0.67 \mathrm{z}$-scores lower than children of nondepressed mothers $(\mathrm{p}=0.010)$. We observed no statistically significant association between CMD and weight-for-length.

Children whose mothers were detected with depression showed, on average, weight-for-age $0.46 \mathrm{z}$-scores lower than children of women without depression ( $\mathrm{p}=0.041$ ). The other exposure variables did not show any statistically significant association with this outcome (Table 4).

Table 2. Bivariate analysis between weight-for-length, weight-for-age, and categorical covariables (simple linear regression). Rio de Janeiro, RJ, Southeastern Brazil, 2005-2008.

\begin{tabular}{lcccccccc}
\hline \multirow{2}{*}{ Variable } & \multicolumn{3}{c}{ Weight-for-length } & & \multicolumn{3}{c}{ Weight-for-age } \\
\cline { 2 - 3 } & Mean & SD & $\mathbf{p}$ & & Mean & SD & $\mathbf{p}$ \\
\hline Prematurity & & & & & & & \\
No & 0.21 & 1.09 & - & & 0.05 & 1.06 & - \\
Yes & 0.18 & 1.02 & 0.906 & & -0.17 & 1.14 & 0.397 \\
Maternal work & & & & & & \\
No & 0.23 & 1.06 & - & & 0.04 & 1.05 & - \\
Yes & 0.28 & 1.19 & 0.797 & 0.07 & 1.15 & 0.860 \\
Maternal age (years) & & & & & & \\
$\geq 20$ & 0.21 & 1.09 & - & & 0.06 & 1.07 & - \\
$<20$ & 0.26 & 1.08 & 0.766 & -0.003 & 1.05 & 0.731 \\
\hline
\end{tabular}

Table 3. Spearman's correlation coefficients between the indexes weight-for-length and weight-for-age and the numerical covariables. Rio de Janeiro, RJ, Southeastern Brazil, 2005-2008.

\begin{tabular}{lccccc}
\hline \multirow{2}{*}{ Variable } & \multicolumn{2}{c}{ Weight-for-length } & & \multicolumn{2}{c}{ Weight-for-age } \\
& Coefficient & $\mathbf{p}$ & & Coefficient & $\mathbf{p}$ \\
\hline Birth weight (grams) & 0.225 & $<0.001$ & & 0.484 & $<0.001$ \\
Maternal education (years of schooling) & -0.046 & 0.485 & & -0.010 & 0.875 \\
Number of children $<5$ years of age & -0.001 & 0.990 & & -0.055 & 0.415 \\
Social network (friends and relatives) & -0.052 & 0.428 & & 0.002 & 0.970 \\
\hline
\end{tabular}

Table 4. Crude and adjusted linear regression coefficients for the association between weight-for-length and weight-for-age with main exposure variables. Rio de Janeiro, RJ, Southeastern Brazil, 2005-2008.

\begin{tabular}{|c|c|c|c|c|c|c|c|c|}
\hline \multirow{3}{*}{ Variable } & \multicolumn{4}{|c|}{ Weight-for-length } & \multicolumn{4}{|c|}{ Weight-for-age } \\
\hline & \multicolumn{2}{|c|}{ Crude } & \multicolumn{2}{|c|}{ Adjusted* } & \multicolumn{2}{|c|}{ Crude } & \multicolumn{2}{|c|}{ Adjusted* } \\
\hline & Coefficient & $\mathbf{p}$ & Coefficient & $\mathbf{p}$ & Coefficient & p & Coefficient & $\mathbf{p}$ \\
\hline CMD (GHQ-12 $\geq 3)$ & -0.080 & 0.585 & -0.053 & 0.714 & 0.022 & 0.882 & 0.048 & 0.708 \\
\hline $\begin{array}{l}\text { More serious disorders } \\
(\mathrm{GHQ}-12 \geq 5)\end{array}$ & -0.393 & 0.019 & -0.368 & 0.026 & -0.025 & 0.884 & -0.014 & 0.928 \\
\hline Depression (GHQ-12 $\geq 9$ ) & -0.674 & 0.011 & -0.667 & 0.010 & -0.474 & 0.065 & -0.463 & 0.041 \\
\hline
\end{tabular}

* Model adjusted by the birth weight variable. 


\section{DISCUSSION}

The results of this study showed that maternal mental health is related to children's nutritional status at six months of life. In the adjusted models we found an association between lower mean weight-for-length z-scores and exposure variables, except CMD. The mean weight-for-age z-score was only associated with maternal depression.

The literature confirms the findings of this study because it has indicated increased risk of child malnutrition in the first six months of life among children of women with postpartum depression ${ }^{14,18,19}$. A recent longitudinal study in Bangladesh found that depression between two and three months postpartum is a risk factor for underweight between six and eight months of age, and prenatal depression is for length-for-age deficit between two and three months and between six and eight months of age ${ }^{14}$.

A meta-analysis of 17 studies on maternal mental health and childhood growth has verified that there is a greater chance of weight- and length-for-age deficits among children of women with depression or depressive and anxious symptoms compared with children of nondepressed women ${ }^{27}$. The effect on these nutritional deficits was greater in the analyses using the diagnosis of depression ${ }^{27}$. The authors also found a greater effect in longitudinal studies, but the exposure investigated in them was to postpartum depression and the result for length-for-age deficit was not significative ${ }^{27}$.

In this study, we noted that the regression coefficient increases with the increase in the severity of exposure, i.e., the association is stronger between nutritional outcomes and more severe disorders and, therefore, depression. As the biological gradient, or dose-response effect, is a relevant criterion to infer causality, the findings of this study, although sectional in nature, reinforce the hypothesis of a causal effect between maternal mental health and child malnutrition. In this context, the exposure effect could only occur beyond certain threshold, which, in the case of this study, would be the presence of more severe mental disorders. Accordingly, the level of exposure of CMD would be below the exposure threshold, which could justify its lack of association with the outcome studied.

There is still no consensus in the literature on the association between maternal CMD and nutritional deficit. While some findings show a positive relationship between these events $^{6,15,21,22}$, others show non-significant or null associations $s^{6,13,15,25}$. The presence of CMD in a single moment may be insufficient to modify the outcomes related to nutritional status.

A recent prospective cohort in Vietnam assessed CMD among mothers in the last trimester of pregnancy or between four and six weeks postpartum (baseline) and again at 15 months postpartum, along with length-for-age. According to the authors, CMD at baseline was not associated with linear growth, but there was a higher risk of maternal CMD at 15 months postpartum among women with perinatal CMD. The persistence of perinatal CMD and CMD at 15 months postpartum was inversely associated with length-for-age at 15 months ${ }^{3}$.

A case-control study conducted in Brazil found nearly twice the chance of weight-for-height deficit in children up to six years of age whose mothers presented $\mathrm{CMD}^{22}$. On the other hand, Stewart et al. ${ }^{25}$ found no association between the presence of CMD and lower postpartum mean z-scores for weight-for-age in children aged nine months. Medhin et al. ${ }^{13}$, in an Ethiopian cohort of more than a thousand participants, observed no effect of CMD in the last trimester of pregnancy, at two months postpartum, or its persistence between these two moments, on weight- or length-for-age at six and 12 months of age, not even in the continuous assessment of these nutritional indexes.

Part of the heterogeneity of results among studies can be explained by the different postpartum moments in which investigations were conducted or by the method of measurement of mental disorders in this phase. Additionally, differences in literature can occur due to different methodologies employed in the choice of the outcome variable or its classification, or due to the use of different anthropometric indicators. In relation to the 
classification of outcome variables, for example, some studies have used the cut-off point of -2 z-scores to detect nutritional deficit in children ${ }^{6,15,22}$ while others used percentiles ${ }^{18}$ or mean z-scores ${ }^{21,25}$. Given this, a comparison of the findings is limited.

The results of the studies also varied according to the indicator used to assess impaired child growth as well as the country in which the study was conducted ${ }^{6,15,25}$. Harpham et al. ${ }^{6}$ observed an association of CMD with length-for-age deficit in India, but not with weight-for-age deficit. The opposite occurred in Vietnam, with a statistically significant association with low weight-for-age and no association with length-for-age. The authors did not find significant results for Peru and Ethiopia. Similar results were found when Nguyen et al..$^{15}$ assessed populations from Bangladesh, Vietnam and Ethiopia. According to some authors, the differences in results may be related to cultural differences in dietary practices and child care among the countries studied, as well as socioeconomic differences such as maternal educational attainment and food security in the house $e^{6,22,27}$.

The potential mechanisms to explain the relationship between maternal mental health and child growth are not clear yet. One hypothesis is that maternal mental health problems may impair the mother's ability to provide proper care for the child, providing inadequate hygiene practices, insufficient food supply and lower bond with the child, which could compromise child growth ${ }^{1}$. Women with depressed mood are more prone to be irritable and hostile to their children and, under these circumstances, may neglect care when the baby is hungry or unable to suck breast milk properly. They may also neglect hygiene and sanitation in food preparation, which can lead to diarrhea and, consequently, to nutritional deficit ${ }^{1,13,15}$.

Postpartum depressive symptoms have been shown to represent a higher risk for premature interruption of breastfeeding, which reflects the mother's inability to provide care in feeding ${ }^{7,19}$. The interruption of breastfeeding harms the evolution of weight gain ${ }^{22}$. Less diverse complementary feeding, energy intake, and frequency of meals have also been reported among children of women with depressive and anxious symptoms ${ }^{8,15}$.

Another potential cause of the relationship between maternal mental health and child malnutrition could be improper maternal health care, as disease prevention and search for care and health services when the child is sick, leading to illness and child malnutrition. Nguyen et al. ${ }^{15}$ showed that maternal CMD are strongly associated with diarrhea and acute respiratory infection.

Despite the hypothesis that mothers' psychological problems may lead to nutritional status compromise in children, there is still no consensus about the temporality of this relationship. Compromised child growth may increase mothers' concerns, promote feelings of inability to care for the child, and increase family pressures, inducing tension, anxiety, and even more serious depressive states ${ }^{9,24}$. Some studies observed that mothers of children with health problems, low birth weight and growth deficit had an increased risk of presenting more severe mental disorders or depression in the first year of the child's life ${ }^{9,20,27}$.

The differences in literature strengthen the need for more longitudinal investigations in the first year after childbirth. It is also necessary to conduct investigations focusing on possible mechanisms that may interfere in these relationships.

Although GHQ-12 is widely used for CMD screening in literature, some studies have recently been using this instrument for more severe disorders and depression ${ }^{17,20}$. Zubaran et al. ${ }^{32}$ observed a significant linear correlation between GHQ-12 and scales widely used to assess postpartum depression (as the Postpartum care Depression Screening Scale [PDSS] and the Edinburgh Postnatal Depression Scale [EPDS]), recommending the use of general health questionnaires for this health condition.

In this perspective, this study contributes to the discussion on the determinants of child growth and confirms the hypothesis of an association between maternal mental health and nutritional deficits in infancy. 
Finally, our results indicate the need for incorporation of mental health into health care policies and programs including prevention and treatment of mental disorders, aiming at improving child nutritional status. In particular, we recommend more careful attention in health services routine, both to mothers of children with nutritional deficits and to children of women with psychological disorders. The use of accessible instruments in health services to detect psychological problems after childbirth has been recommended ${ }^{\mathrm{b}}$. A simple approach would be the inclusion of screening questionnaires as GHQ-12 and team training, aiming to increase the detection of this population in service routines.

\section{REFERENCES}

1. Carvalhaes MABL, Benício MHD. Capacidade materna de cuidar e desnutrição Infantil. Rev Saude Publica. 2002;36(2):188-97. DOI:10.1590/S0034-89102002000200011

2. Caulfield LE, Onis M, Blössner M, Black RE. Undernutrition as an underlying cause of child deaths associated with diarrhea, pneumonia, malaria, and measles. Am J Clin Nutr. 2004;80(1):193-8.

3. Fisher J, Tran T, Nguyen TT, Nguyen H, Tran TD. Common mental disorders among women, social circumstances and toddler growth in rural Vietnam: a population-based prospective study. Child Care Health Dev. 2015;41(6):843-52. DOI:10.1111/cch.12235

4. Goldberg D, Williams P. A user's guide to the General Health Questionnaire. Windsor: NFER-Nelson; 1988.

5. Habicht JP. Estandardización de métodos epidemiológicos quantitativos sobre el terreno. Bol Oficina Sanit Panam. 1974;76(5):375-84.

6. Harpham T, Huttly S, Silva MJ, Abramsky T. Maternal mental health and child nutritional status in four developing countries. J Epidemiol Community Health. 2005;59(12)1060-4. DOI:10.1136/jech.2005.039180

7. Hasselmann MH, Werneck GL, Silva CV. Symptoms of postpartum depression and early interruption of exclusive breastfeeding in the first two months of life. Cad Saude Publica. 2008;24(Suppl 2):341-52. DOI:10.1590/S0102-311X2008001400019

8. Hurley KM, Black MM, Merry BC, Caulfield LE. Maternal mental health and infant dietary patterns in a statewide sample of Maryland WIC participants. Matern Child Nutr. 2015;11(2):229:39. DOI:10.1111/mcn.12004

9. Inandi TO, Elci C, Ozturk A, Egri M, Polat A, Sahin TK. Risk factors for depression in postnatal first year, in eastern Turkey. Int J Epidemiol. 2002;31(6):1201-7. DOI:10.1093/ije/31.6.1201

10. Instituto Brasileiro de Geografia e Estatística. Pesquisa de Orçamentos Familiares 2008-2009: antropometria e estado nutricional de crianças, adolescentes e adultos no Brasil. Rio de Janeiro: Instituo Brasileiro de Geografia e Estatística; 2010.

11. Lapping K, Marsh DR, Rosenbaum J, Swedberg E, Sternin J, Sternin M et al. The positive deviance approach: challenges and opportunities for the future. Food Nutr Bull. 2002;23(4 Suppl):128-35.

12. Mari JJ, Williams P. A comparison of the validity of two psychiatric screening questionnaires (GHQ-12 and SRQ-20) in Brazil, using Relative Operating Characteristic (ROC) analysis. Psychol Med. 1985;15(3):651-9. DOI:10.1017/S0033291700031500

13. Medhin G, Hanlon C, Dewey M, Alem A, Tesfaye F, Lakew Z et al. The effect of maternal common mental disorders on infant undernutrition in Butajira, Ethiopia: The P-MaMiE study. BMC Psychiatry 2010;10:32. DOI:10.1186/1471-244X-10-32

${ }^{\mathrm{b}}$ World Health Organization, Department of Mental Health and Substance Abuse. Maternal mental health and child health and development in low and middle income countries: report of the meeting held in Geneva, Switzerland; 200830 Jan- Feb 2008. Geneva: World Health Organization; 2008.
14. Nasreen HE, Kabir ZN, Forsell Y, Edhborg M. Impact of maternal depressive symptoms and infant temperament on early infant growth and motor development: results from a population based study in Bangladesh. J Affect Disord. 2013;146(2):254-61. DOI:10.1016/j.jad.2012.09.013

15. Nguyen PH, Saha KK, Ali D, Menon P, Manohar S, Mai LT et al. Maternal mental health is associated with child undernutrition and illness in Bangladesh, Vietnam and Ethiopia. Public Health Nutr. 2014;17(6):1318-27. DOI:10.1017/S1368980013001043

16. Olinto MT, Victora CG, Barros FC, Tomasi E. Determinantes da desnutrição infantil em uma população de baixa renda: um modelo de análise hierarquizado. Cad Saude Publica. 1993;9(1 Suppl 1):14-27. DOI:10.1590/S0102-311X1993000500003 
17. Ozdemir H, Remaki M. [General Health Questionnaire-12 for the detection of depression]. Turk Psikiyatri Derg. 2007;18(1):13-21. Turkish.

18. Patel V, DeSouza N, Rodrigues M. Postnatal depression and infant growth and development in low income countries: a cohort study from Goa, India. Arch Dis Child. 2003;88:34-7. DOI:10.1136/adc.88.1.34

19. Rahman A, Iqbal Z, Bunn J, Lovel H, Harrington R. Impact of maternal depression on infant nutritional status and illness: a cohort study. Arch Gen Psychiatry. 2004;61(9):946-52. DOI:10.1001/archpsyc.61.9.946

20. Romito P, Saurel-Cubizolles Mj, Lelong N. What makes new mothers unhappy: psychological distress one year after birth in Italy and France. Soc Sci Med. 1999;49(12):1651-61. DOI:10.1016/S0277-9536(99)00238-5

21. Rondó PH, Rezende G, Lemos JO, Pereira JA. Maternal stress and distress and child nutritional status. Eur J Clin Nutr. 2013;67(4):348-52. DOI:10.1038/ejcn.2013.28.

22. Santos DS, Santos DN, Silva RCR, Hasselmann MH, Barreto ML. Maternal common mental disorders and malnutrition in children: a case-control study. Soc Psychiatry Psychiatr Epidemiol. 2011;46(7):543-8. DOI:10.1007/s00127-010-0220-4

23. Spyrides MHC, Struchiner CJ, Barbosa MTS, Kac G. Amamentação e crescimento infantil: um estudo longitudinal em crianças do Rio de Janeiro, Brasil, 1999/2001. Cad Saude Publica. 2005;21(3):756-66. DOI:10.1590/S0102-311X2005000300009

24. Stewart RC. Maternal depression and infant growth: a review of recent evidence. Matern Child Nutr. 2007;3(2):94-107. DOI:10.1111/j.1740-8709.2007.00088.x

25. Stewart RC, Umar E, Kauye F, Bunn J, Vokhiwa M, Fitzgerald M et al. Maternal common mental disorder and infant growth - a cross-sectional study from Malawi. Matern Child Nutr. 2008;4(3):209-19. DOI:10.1111/j.1740-8709.2008.00147.x

26. Surkan PJ, Ryan LM, Vieira LMC, Berkman LF, Peterson KE. Maternal social and pyschological conditions and physical growth in low-income children in Piauí, Northeast Brazil. Soc Sci Med. 2007;64(2):375-88. DOI:10.1016/j.socscimed.2006.09.021

27. Surkan PJ, Kennedy CE, Hurley KM, Black MM. Maternal depression and early childhood growth in developing countries: systematic review and meta-analysis. Bull World Health Organ. 2011;89(8):607-15. DOI:10.2471/BLT.11.088187

28. United Nations Children's Fund (UNICEF). Improving child nutrition: the achievable imperative for global progress. New York: United Nations Children's Fund; 2013.

29. United Nations Children's Fund, World Health Organization, The World Bank. Levels \& trends in child mortality: report 2014: estimates developed by the UN Inter-agency Group for Child Mortality Estimation. New York: United Nations Children's Fund; 2014 [cited 2015 Feb 10]. Available from: http://www.unicef.org/media/files/Levels_and_Trends_in_Child_ Mortality_2014.pdf

30. Vitolo MR, Gama CM, Bortolini GA, Campagnolo PDB, Drachler ML. Some risk factors associated with overweight, stunting and wasting among children under 5 years old. J Pediatr (Rio J). 2008;84(3):251-7. DOI:10.2223/JPED.1776

31. World Health Organization, Department of Nutrition for Health and Development. WHO Child Growth Standards: Length/height-for-age, weight-for-age, weight-for-length, weight-for-height and body mass index-for-age: methods and development. Geneva: World Health Organization; 2006.

32. Zubaran C, Foresti K, Schumacher MV, Amoretti AL, Thorell MR, Müller, LC. The correlation between postpartum depression and health status. Matern Child Health J. 2010 Sep;14(5):751-7. DOI:10.1007/s10995-009-0512-z

Author's Contribution: Draft: BKH. Structuring of the manuscript: BKH, GLW and MHH. Data collection: BKH. Data analysis and interpretation: BKH, GLW and MHH. Review of the manuscript: GLW and MHH. Project and data collection coordination: $\mathrm{MHH}$.

Conflict of Interest: The authors declare no conflict of interest. 